\title{
EL DERECHO A IMPUGNAR LA SENTENCIA CONDENATORIA*
}

\author{
THE RIGHT TO CHALLENGE \\ THE GUILTY VERDICT
}

Luis Javier Moreno Ortiz

\section{Resumen}

Este artículo pretende determinar tanto el sentido y alcance de la regla hermenéutica constitucional establecida en el inciso segundo del art. 93 de la Carta como el sentido y alcance, merced a la aplicación de dicha regla hermenéutica, del derecho a impugnar la sentencia condenatoria, previsto en el inciso cuarto del art. 29 ibídem. Para ello, se parte de la distinción entre este derecho y el derecho a la doble instancia reconocido en el art. 31 de la Constitución; se propone una hipótesis sobre lo que debe entenderse como interpretación de los derechos y deberes reconocidos en la Constitución conforme a los tratados internacionales sobre derechos humanos ratificados por Colombia. Además, se presentan unos escenarios hipotéticos necesarios para captar los matices que brinda el ordenamiento jurídico colombiano para el ejercicio de este derecho; se analiza el ejercicio del referido derecho en cada escenario, con las dificultades que se siguen de la omisión del legislador de su deber de regularlo y de los efectos dados a la decisión de inexequibilidad en la Sentencia C-792 de 2014; y se concluye que, al tratarse de un derecho constitucional fundamental, su interpretación debe hacerse conforme al principio pro homine, de manera que sea lo más amplia posible y, merced a los principios de igualdad y de favorabilidad, su ejercicio debe estar regulado por la ley y no puede limitarse en el tiempo, a partir de un hito diferente a su reconocimiento por la Constitución o por un tratado internacional que haga parte del bloque de constitucionalidad.

\section{Palabras claves}

Derecho a impugnar la sentencia condenatoria, ejercicio del derecho a impugnar la sentencia condenatoria sin un régimen legal que lo regule, interpretación de la Constitución, interpretación de los derechos conforme a tratados internacionales, reglas hermenéuticas previstas en los tratados.

\footnotetext{
* Artículo reflexión, resultado del proyecto de investigación 'Observatorio de Derecho Público', adelantado por el autor en el Grupo de Investigación 'CREAR', de la Universidad Sergio Arboleda.

** El autor es Licenciado en Filosofía y Humanidades y Abogado de la Universidad Sergio Arboleda, Especialista en Derecho Administrativo del Colegio Mayor de Nuestra Señora del Rosario, Magíster en Derecho de la Universidad Sergio Arboleda y Doctor en Derecho de esta misma casa de estudios.
} 


\begin{abstract}
This article aims to determine both the meaning and scope of the constitutional hermeneutic rule established in the second subsection of art. 93 of the Charter as the meaning and scope, through the application of said hermeneutic rule, of the right to challenge the guilty verdict, provided for in the fourth paragraph of art. 29 ibid. In order to do so, it is based on the distinction between this right and the right to the double instance recognized in art. 31 of the Constitution; a hypothesis is proposed as to what should be understood as an interpretation of the rights and duties recognized in the Constitution in accordance with the international treaties on human rights ratified by Colombia; there are hypothetical scenarios necessary to capture the nuances that the Colombian legal system provides for the exercise of this right; the exercise of this right in each scenario is analyzed, with the difficulties that follow of the omission of the legislator of his duty to regulate it and of the effects given to the decision of unenforceability in Judgment C-792 of 2014; and concludes that, since it is a fundamental constitutional right, its interpretation must be made in accordance with the pro homine principle, so as to be as broad as possible and, by virtue of the principles of equality and favorability, its exercise must be regulated by Law and can not be limited in time, from a milestone different from its recognition by the Constitution or by an international treaty that is part of the constitutionality block.
\end{abstract}

\title{
Keywords
}

Exercise of the right to challenge the guilty verdict without a legal regime that regulates it, hermeneutic rules provided for in treaties, interpretation of the Constitution, interpretation of rights under international treaties, right to challenge the guilty verdict.

\section{Introducción}

La interpretación del texto de la Constitución es una actividad necesaria para establecer su contenido y alcance; esta tarea, en el caso colombiano, no es libre o abierta a cualquier tipo de hermenéutica, sino que tiene una serie de reglas constitucionales y legales que es preciso atender. El sentido de esta actividad depende de lo que se entienda por fuentes del derecho y de lo que se asuma como el papel o función del juez en un determinado contexto (Hinestrosa, 2010). En cuanto a las fuentes parece haber una transición, según lo destaca de manera temprana Fonseca (1992), que en buena parte es continuidad, entre la Ley 153 de 1887 y el art. 230 de la Constitución, lo cual determina un preciso rol del juez, marcado por el mandato del art. 48 de la primera, acorde con el cual el segundo debe decidir, en principio con fundamento en la ley, pero ante su silencio, oscuridad o insuficiencia, también debe resolver, so pena de incurrir en responsabilidad por denegación de justicia, con fundamento en las fuentes auxiliares.

Las reglas legales son más antiguas y, acaso por ello, más conocidas y aplicadas. Están contenidas en la parte primera de la Ley 153 de 1887, todavía vigente, relativa a las 'reglas generales sobre validez y aplicación de las leyes'. Estas reglas fueron pensadas y formuladas en un contexto diferente del actual, en el cual no se reconoce la supremacía de la Constitución, sino que, por el contrario, se presume de derecho la constitucionalidad de las leyes posteriores a ella, incluso si parecen contrarias a su texto. En efecto, el art. $6^{\circ}$ de la ley en comento preveía que "[u]na 
disposición expresa de ley posterior a la Constitución se reputa constitucional, y se aplicará aun cuando parezca contraria a la Constitución". Las implicaciones de esta presunción en el constitucionalismo colombiano han sido analizadas por la doctrina (Cifuentes, 2000; López, 2006; y, Mendieta, 2010).

Si bien las reglas en comento se centran en el fenómeno de la ley y su interpretación, a partir de la convicción de que su texto es, la mayoría de las veces, claro y solo de manera excepcional incongruente, oscuro o dudoso, esta convicción también se extiende a la Constitución al prever que los principios de derecho natural y las reglas de la jurisprudencia "servirán para ilustrar la Constitución en casos dudosos" (art. 4 ibídem), lo cual implica que no se requiere de ellos, valga decir, que no servirán para ilustrarla, en casos no dudosos.

Además de esta alusión a lo que podría tenerse como reglas legales para la interpretación de la Constitución, la ley en cita también prevé que "[l]a doctrina constitucional es, a su vez, norma para interpretar las leyes" (art. 4), lo cual armoniza con lo previsto más adelante en cuanto a que, si la ley "no fuere disposición terminante, sino oscura o deficiente, se aplicará en el sentido más conforme con lo que la Constitución preceptúe" (art. 6), de tal suerte que la doctrina constitucional, al igual que la equidad natural, la crítica y la hermenéutica, "servirán para fijar el pensamiento del legislador y aclarar o armonizar disposiciones legales oscuras o incongruentes" (art. 5). La doctrina constitucional también puede ser útil cuando se está ante un vacío o laguna legal, pues, "[c]uando no hay ley exactamente aplicable al caso controvertido, se aplicarán las leyes que regulen casos o materias semejantes, y en su defecto, la doctrina constitucional y las reglas generales de derecho" (art. 8).

En el año 1910, con el Acto Legislativo 3, al introducirse el principio de supremacía de la Constitución y, con ello, la posibilidad de controlar la constitucionalidad de la ley, incluso si esta es posterior a aquella, las reglas de la Ley 153 de 1887 experimentan un importante cambio (Gómez, 2001; Moreno, 2010; y, Cajas, 2015). No obstante, el asumir la supremacía normativa de la Constitución no implicó de manera necesaria renunciar a la hoy en día centenaria convicción de que el texto de la ley es claro y que sólo cuando ello no sea así, es menester el auxilio de la equidad, los principios generales del derecho y la doctrina, a los que la actual Constitución reconoce como "criterios auxiliares de la actividad judicial" (art. 230), conforme lo sostienen Tamayo \& Jaramillo (2012).

Las reglas constitucionales no son tan visibles ni evidentes como las antedichas reglas legales. Se encuentran inmersas en la parte final del Capítulo IV del Título II de la Constitución, que regula la especie de la protección y aplicación de los derechos dentro del género de los derechos, las garantías y los deberes, conforme a los añejos y todavía útiles criterios de clasificación aristotélicos. Esta poca visibilidad quizá se deba a las formidables instituciones que las preceden y que pueden tenerse, con razón, como las principales y más valiosas novedades de la Constitución de 1991, entre las cuales sobresalen el principio de buena fe, la aplicación inmediata 
de las normas que reconocen algunos derechos, la acción de tutela, la acción de cumplimiento, las acciones populares y de grupo y la responsabilidad patrimonial del Estado.

La existencia de reglas constitucionales para interpretar la Constitución es una verdadera novedad en la tradición jurídica nacional, pues, como se acaba de ver, la Constitución de 1886 no se ocupaba de esta materia, que fue asumida por la Ley 153 de 1887, y tampoco hubo una consciente y clara intención de hacerlo en las numerosas reformas que se le hicieron a la Carta en su centenaria existencia. De esta novedad ha tomado nota la jurisprudencia de la Corte Constitucional (Arango, 2004; Olano, 2005), al estudiar el fenómeno del bloque de constitucionalidad. Esta nueva visión también converge con desarrollos recientes en torno al fenómeno del control de convencionalidad y al principio de interpretación conforme a los tratados internacionales sobre derechos humanos (Henderson, 2004; Sagüés, 2010; Ferrer, 2011; Santolaya; 2013; y, Caballero, 2011).

Estas reglas están previstas en el inciso segundo del art. 93 y en el art. 94 de la Constitución y su sujeta materia es la interpretación de las normas constitucionales relativas a los derechos y a los deberes. La primera de ellas, suele confundirse con la contenida en el inciso primero del mismo artículo, relativa al bloque de constitucionalidad en sentido normativo, valga decir, de las normas jurídicas que tienen rango y jerarquía de normas constitucionales, así no estén contenidas en el texto de la Constitución, sino en tratados internacionales sobre derechos humanos. Esta confusión genera notables dificultades, pues, a pesar de estar en el mismo artículo, el alcance de las dos reglas es disímil, tanto en su supuesto de hecho como en su consecuencia de derecho.

El supuesto de hecho de la primera norma, plasmada en el primer inciso del art. 93 de la Constitución, se funda en tres condiciones: (i) que se trate de un tratado o convenio internacional ratificado por la República (es un lapsus calami decir ratificados por el Congreso, pues este aprueba, pero no ratifica tratados o convenios); (ii) que el tratado o convenio reconozca derechos humanos; y (iii) que el tratado o convenio prohíba la limitación de tales derechos en los estados de excepción. La segunda norma, contenida en el segundo inciso del mismo artículo, solo prevé las dos primeras condiciones y, vale la pena destacarlo, lo hace sin incurrir en el antedicho lapsus calami. Es obvio que al no exigirse en el supuesto de hecho de la segunda regla la tercera condición, el conjunto de posibles tratados o convenios o, en rigor, de contenido de los mismos, que satisface este supuesto de hecho será mayor al conjunto que satisfaga tal condición, como se analizará en el desarrollo de este escrito.

La consecuencia de derecho de la primera norma es la prevalencia en el orden interno, mientras que la de la segunda es el deber de interpretación conforme a los tratados o convenios. La prevalencia puede tener importantes efectos normativos al brindar a normas contenidas en los convenios o tratados, al menos, el mismo rango y jerarquía de las normas contenidas en la Constitución, como lo sostiene la 
Corte Constitucional en su doctrina del bloque de constitucionalidad, o un rango y jerarquía que podría ser superior, como podría seguirse de los argumentos dados por la Corte Interamericana de Derechos Humanos en su doctrina del control de convencionalidad, o como podría sostenerse en un momento dado para proponer un desarrollo de la doctrina de la Corte Constitucional sobre la sustitución de la Constitución.

La interpretación conforme tiene, sin duda, efectos hermenéuticos, al brindar un referente necesario (nótese que la Constitución no fija condiciones, como lo hacían las reglas legales examinadas, al referirse a "ilustrar la Constitución en casos dudosos"), que tiene consecuencias tanto para la inteligencia de la propia Constitución como de la ley. Las tiene para la Constitución, en cuanto atañe a los derechos y deberes que reconoce, los cuales deben interpretarse siempre conforme a los tratados internacionales sobre derechos humanos. Las tiene para la ley, porque esta debe interpretarse siempre del modo más conforme con la Constitución, de lo que se sigue, como consecuencia obvia, que la ley debe interpretarse, en tanto desarrolle o regule derechos y deberes reconocidos por la Constitución, conforme a dichos tratados.

La segunda regla, contenida en el art. 94 de la Constitución, es más compleja y difícil que la anterior, en la medida en que emplea referentes no normativos y, lo que es más delicado para una mentalidad positiva, no textuales. Su supuesto de hecho es el vacío de la Constitución y de los tratados internacionales sobre derechos humanos, circunstancia poco frecuente en la práctica, pues, para poder aplicarse, se requiere que ninguno de los anteriores textos reconozca de forma expresa un derecho (de ahí la alusión que la doctrina hace a los derechos innominados). Su consecuencia de derecho es que este vacío no debe entenderse como negación de otros derechos que sean inherentes a la persona humana. Se trata, pues, de una prohibición hermenéutica que impide al operador jurídico atribuir al vacío o a las omisiones de la Constitución y de los tratados la consecuencia de negar un derecho inherente a la persona humana.

El esbozo de las reglas existentes para interpretar la Constitución, en especial de la primera de las reglas constitucionales, la prevista en el inciso segundo del art. 93, brinda el contexto para la presente investigación, cuyo propósito es interpretar conforme a dicha regla el derecho a impugnar la sentencia condenatoria, reconocido por el art. 29 de la Constitución a quien sea sindicado. No se trata, como podría pensarse a primera vista, de un mero estudio de caso o de la crítica de la Sentencia C-792 de 2014, sino de algo de mayor calado, esto es, de plantear el problema de cómo debe interpretarse el referido derecho conforme a los tratados internacionales sobre derechos humanos ratificados por Colombia y, sobre todo, de establecer cuál o cuáles son los referentes relevantes de dichos tratados al momento de realizar la susodicha interpretación.

Se propone, pues, un ejercicio que pretende combinar la necesaria profundidad teórica de una investigación científica sobre el sentido y alcance de la regla de 
hermenéutica constitucional de interpretación de los derechos y deberes constitucionales conforme a tratados internacionales, con la no menos necesaria utilidad práctica de una investigación científica sobre el sentido y alcance de un derecho en particular: el derecho del sindicado a impugnar la sentencia condenatoria, que tiene notables implicaciones constitucionales, penales y procesales para nuestra realidad.

Para que este propósito sea posible es necesario asumir, como punto de partida, conforme lo hace la Corte Constitucional en la aludida sentencia, la distinción entre el derecho a impugnar la sentencia condenatoria y la doble instancia. Alinderado el derecho a impugnar la sentencia condenatoria, se debe asumir la tarea de interpretar la regla hermenéutica del inciso segundo del art. 93 de la Constitución y, al hacerlo, proponer una hipótesis al respecto, al menos a partir de dos de los referentes más reconocidos: la Convención Americana sobre Derechos Humanos (CADH) y el Pacto Internacional de Derechos Civiles y Políticos (PIDCP). Fijados así el parámetro constitucional y su interpretación, se debe elaborar un discurso que, sin dejar de ser abstracto, responda de manera adecuada a las diversas situaciones que en nuestro ordenamiento jurídico pueden darse, por medio de escenarios hipotéticos, a fin de no simplificar en exceso la cuestión y de evitar, con ello, un análisis irrespetuoso de las particularidades de cada situación general posible. Determinados los escenarios o espacios hipotéticos, se procederá a interpretar el derecho en cada uno de ellos y, en esta actividad, se considerarán las dificultades que tiene su ejercicio en el tiempo y las circunstancias que se siguen de la omisión del legislador de su deber de regular dicho ejercicio.

\section{La distinción entre el derecho a impugnar la sentencia condenatoria y la doble instancia}

Un presupuesto necesario para el análisis del derecho a impugnar la sentencia condenatoria es el de superar la confusión existente entre este y el derecho a apelar o a la consulta de una sentencia judicial. Si bien entre ambos derechos hay varios aspectos en común, que podrían situarlos en un mismo género: el derecho a impugnar sentencias, existen, como se verá en detalle, aspectos que permiten diferenciarlos y que hacen de ellos dos especies distintas.

Una primera aproximación a los derechos en comento, en el plano solo normativo constitucional, revela que su regulación está contenida en diferentes artículos de la Carta: en el inciso cuarto del art. 29 (derecho a impugnar la sentencia condenatoria) y en el inciso primero del art. 31 (derecho a apelar la sentencia judicial o a la consulta de la misma). En el primero, al ocuparse del proceso criminal, que es el único en el cual existe el sujeto procesal del sindicado, la Constitución prevé que:

Toda persona se presume inocente mientras no se le haya declarado judicialmente culpable. Quien sea sindicado tiene derecho a la defensa y a la asistencia de un abogado escogido por él, o de oficio, durante la investigación y el juzgamiento; a un debido proceso público sin dilaciones injustificadas; a presentar pruebas y a contro- 
vertir las que se alleguen en su contra; a impugnar la sentencia condenatoria, y a no ser juzgado dos veces por el mismo hecho.

En el segundo, al hacer referencia sin distinciones a las sentencias proferidas por los jueces de la República, la Constitución dispone que "[t]oda sentencia judicial podrá ser apelada o consultada, salvo las excepciones que consagre la ley". Las dos regulaciones constitucionales transcritas tienen en común el reconocer a las personas el derecho a impugnar sentencias, circunstancia que acaso haya propiciado la confusión entre ambas para sostener que se trata del mismo derecho. No obstante, existen aspectos objetivos distintos, como son los relativos al sujeto del derecho, a su objeto, al contexto de su ejercicio y al margen de configuración del legislador. En efecto:

(i) El sujeto del derecho a apelar las sentencias judiciales o a la consulta de las mismas, aunque no se dice de forma expresa, es cualquier persona que sea sujeto procesal o que tenga tal condición. El sujeto del derecho a impugnar la sentencia condenatoria, según la previsión clara de la norma constitucional, es solo el sindicado, de tal suerte que otros sujetos procesales del proceso penal, como la fiscalía o las víctimas, $\mathrm{u}$ otros intervinientes, como el ministerio público, no son titulares de este derecho;

(ii) El objeto del derecho previsto en el art. 31 tiene una determinación precisa, pues se refiere a apelar o a la consulta de sentencias judiciales, por lo que en él no hay cabida para otros recursos ordinarios o extraordinarios, ni para otro tipo de mecanismos de protección de derechos. El objeto del derecho reconocido en el artículo 29 está menos determinado, puesto que se refiere a impugnar la sentencia, lo cual puede hacerse a través de diversos medios de impugnación, entre ellos los recursos y, dentro de estos, el de apelación, de tal suerte que no es posible identificar apelación con impugnación, siendo esta última categoría mucho más amplia que la primera;

(iii) El contexto del derecho a apelar las sentencias judiciales o a su consulta está dado por dos pautas objetivas: una, que se trate de una sentencia judicial, lo cual excluye otro tipo de providencias judiciales, como son los autos, y, otra, que esta sentencia haya sido proferida por una autoridad que cumpla funciones judiciales, sea que se interprete de manera restringida para afirmar que esta autoridad debe ser siempre un juez, o que ello se haga de forma más amplia para incluir también autoridades administrativas, particulares $\mathrm{u}$ otras de las autoridades que cumplen funciones judiciales según lo previsto en el artículo 116 de la Carta. El contexto del derecho a impugnar la sentencia condenatoria, si bien puede enmarcarse dentro de las antedichas pautas objetivas, requiere de una tercera pauta específica: que se trate de una sentencia proferida por un juez penal, pues en procesos distintos al penal no existe el sujeto procesal del sindicado. Este contexto también puede interpretarse de manera restringida para sostener que solo son jueces penales las autoridades judiciales de la jurisdicción ordinaria (jueces, tribunales y sala de casación penal de 
la Corte Suprema de Justicia), o de manera más amplia para incluir, además, a los jueces penales militares y a la justicia indígena;

(iv) Como ya se advirtió, el margen de configuración del legislador respecto del derecho a apelar sentencias judiciales o a su consulta es amplio, en la medida en que la propia Constitución faculta a esta autoridad para establecer excepciones a la regla, sin mayores condiciones o exigencias. Respecto del derecho a impugnar la sentencia condenatoria no existe una autorización constitucional semejante en términos explícitos, ni parece poder haberla en términos implícitos, pues este derecho tiene, en tanto garantía del sindicado, un papel equivalente al derecho a la defensa, a la asistencia de un abogado, a presentar y controvertir pruebas y a no ser juzgado dos veces por el mismo hecho, como garantía mínima e irrenunciable. En estas condiciones el margen de configuración del legislador es mucho más reducido, para permitirle, por ejemplo, regular el modo de ejercer el derecho, valga decir, si se trata de un recurso o de otro instrumento, pero no para establecer excepciones al mismo, bajo la forma de prohibiciones o de exclusiones, referidas a la persona del sindicado, al tipo de delito o al juez penal que profiere la sentencia.

En vista de las anteriores circunstancias, no debe generar sorpresa que las normas contentivas de las excepciones previstas por la ley al derecho a apelar la sentencia judicial o a su consulta, hayan sido declaradas exequibles por la Corte Constitucional en diversas oportunidades, incluso en el contexto del proceso penal. Así ha ocurrido respecto de las sentencias de los jueces de familia (Sentencias C-1005 de 2005 y C-718 de 2012), de los jueces administrativos (Sentencia C-040 de 2002), de los jueces civiles especializados en restitución de tierras (Sentencia C-099 de 2013), de los jueces civiles (Sentencias C-103 de 2005 y C-726 de 2014), e incluso de los jueces penales (Sentencias C-411 de 1997 y C-934 de 2006).

Si se dejan de lado los procesos distintos al penal, para los cuales es irrelevante el derecho del sindicado a impugnar la sentencia condenatoria, dado que en ellos no existe sindicado, al haberse centrado el análisis constitucional de las normas penales o procesales penales que impiden la impugnación de la sentencia condenatoria en el marco previsto en el art. 31 de la Constitución, no era irrazonable que la conclusión fuese la de que su titular no tiene derecho a apelar o a la consulta de la sentencia proferida por el juez penal. Sin embargo, este análisis específico, que prima facie puede parecer irreprochable, omite considerar el derecho a impugnar la sentencia condenatoria, previsto en el inciso cuarto del art. 29 de la Constitución, a partir del cual la circunstancia de que el derecho a apelar la sentencia judicial admita excepciones (fijadas por la ley) no es suficiente para desconocer las garantías mínimas del sindicado en el proceso penal, una de las cuales es el derecho a impugnar la sentencia condenatoria (Moreno \& Lozano (2011).

El comprensible proceder de la Corte Constitucional, pero no por ello irreprochable, dado que omitir considerar el derecho fundamental del sindicado a impugnar la sentencia condenatoria -además de la afectación de la Carta Política implica la vulneración de, al menos, dos normas contenidas en tratados internacionales 
sobre derechos humanos, como son la Convención Americana sobre Derechos Humanos y el Pacto Internacional de Derechos Civiles y Políticos, que hacen parte del bloque de constitucionalidad-, fue, en buena hora, rectificado en la Sentencia C-792 de 2014, en la cual se reconocen de manera expresa las diferencias existentes entre los derechos sub examine.

\section{La interpretación del derecho del sindicado a impugnar la sentencia condenatoria conforme a la Convención Americana sobre Derechos Humanos y al Pacto Internacional sobre Derechos Civiles y Políticos}

Luego de distinguir entre el derecho de toda persona que hace parte de un proceso judicial, valga decir, que es un sujeto procesal o un interviniente, a impugnar la sentencia o a que se surta la consulta de la misma, del derecho del sindicado en el proceso penal a impugnar la sentencia condenatoria, podría pensarse que el texto del cuarto inciso del art. 29 es bastante claro para, en los términos de la Ley 153 de 1887 (el referente hermenéutico más conocido), que no sea necesario proceder a interpretarlo, pues su sentido es unívoco.

Como se propuso en la introducción de este estudio, la hermenéutica de la Constitución, cuando se trata de derechos y deberes y de su sentido y alcance, no está regida por las reglas de la Ley 153 de 1887, ni tampoco es un asunto librado al discernimiento de los operadores jurídicos. En efecto, según lo previsto en el segundo inciso del art. 93 de la Carta, los derechos y deberes reconocidos en ella se interpretarán conforme a los tratados internacionales sobre derechos humanos ratificados por Colombia.

El mandato constitucional no entra en las distinciones decimonónicas, propias de la Ley 153 de 1887, entre textos claros y oscuros, ni califica a los susodichos tratados como fuentes auxiliares. Según este mandato todos los derechos y deberes constitucionales, en todos los casos, deben interpretarse conforme a los tratados internacionales, al punto de que podría hablarse del principio de interpretación conforme a los tratados de los derechos y deberes. Así, pues, los tratados en comento son un elemento de juicio indispensable al momento de establecer el alcance y el sentido de tales derechos y no una mera opción a considerar. Esta es la hipótesis que se sostiene en este escrito y es, también, la que permite comprender, en el análisis concreto, el sentido y alcance del derecho del sindicado a impugnar la sentencia condenatoria.

El ejercicio de interpretación que se propone del aludido derecho constitucional está incompleto, como también lo está, valga decirlo, en la Sentencia C-792 de 2014, pues solo emplea dos tratados internacionales sobre derechos humanos ratificados por Colombia, la Convención Americana sobre Derechos Humanos y el Pacto Internacional de Derechos Civiles y Políticos, cuando en rigor, debería atender también a los demás. En este sentido la aproximación que se propone debe ser mejorada, aunque con lo que se hace es suficiente para demostrar las implicaciones de la hipótesis planteada. 
La interpretación conforme a los tratados debe examinarse a partir de dos cuestiones, que no son en modo alguno incompatibles, a saber: el derecho constitucional debe interpretarse conforme al derecho humano correspondiente del tratado o el derecho constitucional debe interpretarse conforme a las reglas hermenéuticas previstas en el tratado. Para configurar la hipótesis planteada, se propone responder de manera afirmativa ambas cuestiones, es decir, que la interpretación conforme al tratado del derecho implica tanto interpretarlo conforme al derecho humano correspondiente como a las reglas hermenéuticas previstas en el tratado, en un ejercicio sistemático que, vale la pena no desconocerlo, puede resultar complejo. Este escenario podría ser aún más difícil si se considera, como lo hace de forma explícita la Corte Constitucional (Sentencia C-327 de 2016), la interpretación conforme a la Constitución de los tratados internacionales sobre derechos humanos, lo cual exige una hermenéutica sistemática de doble vía, que puede ser incluso más complicada. Sin entrar, de momento en esta hondura, se debe explorar la interpretación conforme al tratado, a partir de las dos opciones propuestas.

Si se sigue la primera opción, se encuentra que el derecho humano que corresponde al derecho constitucional del sindicado a impugnar la sentencia condenatoria, está previsto en el art. 8 de la Convención Americana sobre Derechos Humanos y en el art 14 del Pacto Internacional de Derechos Civiles y Políticos. En efecto, el referido art. 8, relativo a las garantías judiciales, prevé en su numeral 2 una serie de garantías mínimas para "[t]oda persona inculpada de delito" durante el proceso, entre las cuales se encuentra, en el literal h, el "derecho de recurrir el fallo ante juez o tribunal superior"; y el mencionado artículo, en su numeral 5, dispone que "[t] oda persona declarada culpable de un delito tendrá derecho a que el fallo condenatorio y la pena que se le haya impuesto sean sometidos a un tribunal superior, conforme a lo prescrito por la ley".

Es evidente que el derecho constitucional en mención, que es un derecho fundamental, coincide de manera precisa con los derechos humanos reconocidos en tales tratados, en sus aspectos definitorios, a saber: (i) su titular es el sindicado, inculpado o declarado culpable de un delito; (ii) su objeto es impugnar, recurrir o someter ante un tribunal superior la sentencia condenatoria. Hay, sin embargo, una diferencia que puede ser relevante, pues la Constitución no se refiere a un tribunal superior, sino que reconoce el derecho a impugnar la sentencia condenatoria sin mayores distinciones, mientras que ambos tratados si se refieren de forma expresa a dicho tribunal superior, con lo cual parecería, al menos prima facie, que el texto constitucional adopta una forma amplia: "impugnar", en la cual cabrían diversos medios de impugnación o recursos que pueden no ser siempre el de apelación, mientras que el texto de los tratados parece adoptar una forma más restringida y referirse a recursos que se conocen por un juez o tribunal superior, circunstancia que en el contexto del ordenamiento jurídico colombiano parece encajar de manera precisa con el recurso de apelación y de manera imprecisa, aunque posible, en los medios de impugnación extraordinarios de casación y de revisión. 
Si se sigue la segunda opción, es menester considerar los arts. 27 y 29 de la Convención Americana sobre Derechos Humanos y los arts. 4 y 5 del Pacto Internacional de Derechos Civiles y Políticos. En efecto, para interpretar un derecho, antes de considerar su hermenéutica, es necesario determinar si, conforme al texto del tratado, es de aquellos que pueden o no suspenderse, incluso bajo estados de excepción, valga decir, si se trata de un derecho intangible. Por ello, se deben aplicar los referidos arts. 27 y 4, para determinar si los derechos reconocidos en los arts. 8 y 14 tienen tal condición y, al hacerlo, se constata que no son derechos intangibles, por lo que sí pueden suspenderse de manera excepcional, siempre que sea estrictamente necesario dadas las circunstancias.

En vista de que no se trata de derechos intangibles, se debe proceder al análisis de las normas hermenéuticas de ambos tratados, previstas en los siguientes términos:

Artículo 29. Normas de Interpretación

Ninguna disposición de la presente Convención puede ser interpretada en el sentido de:

a) permitir a alguno de los Estados Partes, grupo o persona, suprimir el goce y ejercicio de los derechos y libertades reconocidos en la Convención o limitarlos en mayor medida que la prevista en ella;

b) limitar el goce y ejercicio de cualquier derecho o libertad que pueda estar reconocido de acuerdo con las leyes de cualquiera de los Estados Partes o de acuerdo con otra convención en que sea parte uno de dichos Estados;

c) excluir otros derechos y garantías que son inherentes al ser humano o que se derivan de la forma democrática representativa de gobierno, y

d) excluir o limitar el efecto que puedan producir la Declaración Americana de Derechos y Deberes del Hombre y otros actos internacionales de la misma naturaleza.

Artículo 5.

1. Ninguna disposición del presente Pacto podrá ser interpretada en el sentido de conceder derecho alguno a un Estado, grupo o individuo para emprender actividades o realizar actos encaminados a la destrucción de cualquiera de los derechos y libertades reconocidos en el Pacto o a su limitación en mayor medida que la prevista en él.

2. No podrá admitirse restricción o menoscabo de ninguno de los derechos humanos fundamentales reconocidos o vigentes en un Estado Parte en virtud de leyes, convenciones, reglamentos o costumbres, so pretexto de que el presente Pacto no los reconoce o los reconoce en menor grado.

Estas normas resultan cruciales al momento de interpretar tanto los derechos humanos reconocidos por los tratados como los derechos y deberes previstos en la Constitución Política, pues establecen, en lo relevante para este asunto, una serie de límites y de criterios al momento de señalar el alcance y sentido de los derechos 
constitucionales. En cuanto a los límites, se debe destacar el límite común de que no se puede suprimir o limitar los derechos en mayor medida que la prevista en los tratados. En relación con los criterios, se debe señalar el de que cuando concurren varias normas, sean internacionales o nacionales, en el reconocimiento del derecho, no se puede optar por aquella que los reconoce en menor grado, sino que se debe seguir aquella que los reconoce en mayor grado, es decir, de modo más favorable al ser humano (principio pro homine).

Conforme a estas pautas es posible concluir, incluso antes de estudiar los escenarios hipotéticos, de manera general, que: (i) tanto en la Constitución como en los tratados se reconoce el derecho del sindicado, inculpado o declarado culpable en un proceso penal a impugnar o recurrir la sentencia condenatoria, de manera que impedir o limitar el goce y ejercicio de este derecho vulnera la Constitución y desconoce los referidos tratados, de lo que puede seguirse la responsabilidad de las personas que impiden o limitan y del propio Estado; (ii) ni la Constitución ni los tratados limitan de forma expresa el derecho a partir de la circunstancia del juez que profiere la sentencia, aunque así podría seguirse de la recurrente mención que se hace en los tratados del juez o tribunal superior. Lo relevante para el ejercicio del derecho en comento parece ser que una persona haya sido condenada por un juez en un proceso penal, lo que puede acaecer en el contexto colombiano en múltiples y variados escenarios hipotéticos, como pasa a verse.

\section{Los escenarios hipotéticos para el ejercicio del derecho a impugnar la sentencia condenatoria}

La condena del sindicado en el proceso penal, valga decir, su declaración de responsabilidad, puede acaecer en diversas circunstancias teóricas. De ellas se puede dar cuenta, a partir del diseño normativo del proceso, en especial de la competencia de cada juez o tribunal y de los recursos existentes, por medio de una serie de escenarios hipotéticos, que van de la situación más común: la del ciudadano de la calle, hasta la del que se desempeña como servidor público en un cargo de alta responsabilidad, como es el caso de los aforados constitucionales.

La existencia simultánea de dos procedimientos penales: los previstos en las Leyes 600 de 2000 y 906 de 2004, que tienen entre sí notables diferencias, unida a la multiplicidad de autoridades judiciales en materia penal: jueces (municipales, del circuito y del circuito especializados), tribunales y Corte Suprema de Justicia, generan una serie de variables complejas, que es necesario analizar en detalle.

La Ley 600 de 2000, conforme a lo dispuesto en el art. 533 de la Ley 906 de 2004, solo se aplica al supuesto previsto en el art. 235.3 de la Constitución, que regula la investigación y el juzgamiento de los miembros del Congreso. Esta situación excepcional no incide en la tarea de plantear los escenarios hipotéticos, pues, en todo caso, en estos eventos se mantiene inalterada la competencia de la Corte Suprema de Justicia, que es el factor relevante para tal propósito. Por ello, no es necesario profundizar en el análisis de esta circunstancia. 
La conducta del ciudadano de la calle, con independencia de su gravedad, es conocida y juzgada por un juez de la República. La mayoría de las veces este juez es el municipal, al que se le otorga competencia para ocuparse de asuntos que suelen ser corrientes en su existencia como las lesiones personales, los crímenes de menor cuantía contra el patrimonio económico, los delitos de violencia intrafamiliar e inasistencia alimentaria, e incluso de los delitos contra los animales, entre otros (art. 37 de la Ley 906 de 2004 modificado por las Leyes 1142 de 2007, 1273 de 2009 y 1774 de 2016). Si la conducta es muy grave, como ocurre en general con la que implica la infracción al derecho internacional humanitario y la comisión de genocidio, delitos de lesa humanidad o crímenes de guerra, o con los delitos propios de las organizaciones criminales, o de los que tienen relación con el terrorismo, el narcotráfico y el lavado de activos, entre otros, según lo dispuesto en el art. 35 de la Ley 906 de 2004, la competencia es del juez penal del circuito especializado. Por último, las conductas que no se enmarquen dentro de las competencias de los dos jueces anteriores, conforme a lo previsto en el art. 36 de la Ley 906 de 2004, corresponden al juez penal del circuito. Para el propósito de plantear los escenarios hipotéticos, no es necesario ahondar en estas competencias, en la medida en que el recurso de apelación contra las sentencias proferidas por cualquiera de estos jueces debe ser resuelto, al tenor de lo dispuesto en los arts. 33 y 34 de la Ley 906 de 2004, por el tribunal superior de distrito judicial.

La conducta de algunos ciudadanos, que tienen la condición de servidores públicos, es conocida y juzgada por los tribunales superiores de distrito judicial o por la propia Corte Suprema de Justicia. Tal es el caso de los jueces, procuradores, personeros y fiscales, cuando actúan en el proceso penal, cuya conducta es conocida y juzgada por los tribunales superiores de distrito judicial (arts. 33.2 y 34.2 de la Ley 906 de 2004), y de los servidores enunciados en los arts. 174 y 235 de la Constitución, entre los cuales se encuentra el presidente de la República, los ministros del despacho, los magistrados de las cortes de cierre, el fiscal general de la nación, el procurador general de la nación, el defensor del pueblo, el contralor general de la república, los agentes del ministerio público los congresistas y el registrador nacional del estado civil, entre otros, cuya conducta es conocida y juzgada por la Sala de Casación Penal de la Corte Suprema de Justicia, conforme a lo previsto en el art. 32 de la Ley 906 de 2004.

Sobre la base de las antedichas competencias, es posible plantear cuatro posibles escenarios hipotéticos respecto del ciudadano de la calle en el contexto del proceso penal, como pasa a verse. En efecto, a partir de la circunstancia de que el ciudadano sea condenado por el juez (municipal, del circuito o del circuito especializado), se configura el primer escenario hipotético, que no ofrece ningún problema respecto del derecho a impugnar la sentencia condenatoria, pues la ley reconoce este derecho y regula su ejercicio (arts. 20, 176 y 179 de la Ley 906 de 2004), de tal suerte que la decisión pasa a ser revisada por su superior jerárquico: el tribunal superior de distrito judicial respectivo (arts. 33.1 y 34.1 de la Ley 906 de 2004). No obstante, si el ciudadano no es condenado por el juez y los sujetos procesales o intervinientes, conforme a lo previsto en el artículo 176 de la Ley 906 de 2004, apelan 
la sentencia absolutoria, se presenta la circunstancia de que el tribunal revisará su conducta dando lugar al planteamiento de los escenarios hipotéticos siguientes.

El segundo escenario se configura si el tribunal decide confirmar la sentencia absolutoria. Este escenario tampoco genera problemas para el derecho a impugnar la sentencia condenatoria, dado que, por sustracción de materia, no existe una sentencia condenatoria, de tal suerte que el sindicado carece de interés alguno para impugnar la sentencia que lo absuelve.

No puede decirse lo mismo del tercer escenario, que se configura si el tribunal decide revocar la sentencia absolutoria y, en su lugar, condenar al ciudadano. Al sobrevenir la condena en el trámite de la segunda instancia, el derecho del ciudadano a impugnar la sentencia condenatoria queda muy restringido. En efecto, no le es posible ejercer el derecho de apelación, previsto solo para las sentencias dictadas por el tribunal en primera instancia (art. 32.3 de la Ley 906 de 2004), sino que apenas estarían a su alcance -en el evento de configurarse alguna de sus causales- los recursos extraordinarios de casación y de revisión y la acción de tutela.

La situación del segundo escenario puede cambiar si los intervinientes recurren en casación la sentencia absolutoria (art. 182 de la Ley 906 de 2004) y la Corte Suprema de Justicia decide revocar la sentencia del tribunal y, en su reemplazo, profiere una sentencia condenatoria, dando lugar a un cuarto escenario hipotético. La suerte del ciudadano en este escenario es peor que la del tercer escenario, pues ya no tiene a su alcance el recurso de casación y sus posibilidades de impugnar la sentencia condenatoria se reducen al recurso extraordinario de revisión y a la acción de tutela.

A los cuatro escenarios hipotéticos que es posible plantear para el ciudadano de la calle, es necesario agregar los que corresponden a los dos grupos de servidores públicos que tienen un tratamiento especial en su juzgamiento, valga decir, a las personas juzgadas por el tribunal superior de distrito judicial y por la Corte Suprema de Justicia, como se hace enseguida.

Respecto de las personas cuya conducta juzga el tribunal es posible plantear escenarios hipotéticos análogos a los tres primeros. En efecto, si la sentencia es condenatoria, lo cual configura el quinto escenario hipotético, no hay reparo alguno respecto del derecho a impugnar la sentencia condenatoria, pues el art. 32.3 de la Ley 906 de 2004 prevé que esta es apelable ante su superior jerárquico: la Corte Suprema de Justicia; si la sentencia es absolutoria y no se impugna, lo cual configuraría el sexto escenario hipotético, tampoco habría reparo porque, por sustracción de materia, el sindicado carecería de interés en impugnarla; no obstante, la situación cambia si la sentencia es absolutoria, se impugna y en el trámite del recurso de apelación la Corte Suprema de Justicia decide revocarla y, en su lugar, proferir una condena, que es el séptimo escenario, pues en este evento la sentencia solo sería susceptible de cuestionarse por medio del recurso extraordinario de revisión y por la acción de tutela, en una situación tan limitada como la ya descrita en el cuarto escenario. 
Respecto de las personas cuya conducta juzga la Corte Suprema de Justicia se pueden configurar los dos escenarios restantes. El octavo, cuando la sentencia es absolutoria, en el cual se reitera la no afectación del derecho del sindicado por sustracción de materia. Y el noveno, cuando la sentencia es condenatoria, en el cual se está en la misma situación de los escenarios cuarto y séptimo, es decir, con la limitada posibilidad de impugnar la sentencia por medio del recurso extraordinario de revisión y por la acción de tutela.

No es posible plantear otros espacios hipotéticos, en razón a las posibles variables que ocurrirían merced al recurso extraordinario de revisión y a la acción de tutela contra providencias judiciales. Y no lo es, porque en el trámite de dicho recurso solo se profiere una decisión de fondo, cuando se encuentra configurado el fenómeno de la prescripción de la acción penal, la ilegitimidad del querellante, la caducidad de la querella, la extinción de la acción penal o un cambio de criterio favorable al condenado, circunstancias en las cuales este no tiene ningún interés para recurrir o impugnar, y en los demás casos la actuación se devuelve a un despacho de la misma categoría del autor de la decisión para que tramite de nuevo el proceso, con lo cual se reabre lo dicho en los nueve escenarios ya planteados. Y tampoco lo es, porque, si bien en el trámite de la acción de tutela, ya sea de manera provisional o ya definitiva, se puede amparar el derecho fundamental y, en consecuencia, dejar sin efectos la sentencia judicial, en todo caso el juez constitucional no puede proferir una sentencia de reemplazo, sino que ordena al juez ordinario que lo haga, con lo cual se abren de nuevo los conocidos escenarios.

En síntesis, para el ejercicio del derecho del sindicado a impugnar la sentencia condenatoria el primero, el segundo, el quinto, el sexto y el octavo de los escenarios hipotéticos no ofrecen ninguna dificultad, pues en todos ellos el ordenamiento jurídico lo reconoce y garantiza. Sin embargo, en casi la mitad de ellos: el tercero, el cuarto, el séptimo y el noveno, el ejercicio de este derecho sufre importantes restricciones, que son menos severas en el tercer escenario, en el que puede proceder el recurso extraordinario de casación, y más severas en los demás, en los cuales no procede este medio de impugnación.

En vista de la anterior circunstancia corresponde analizar las condiciones normativas para el ejercicio del derecho a impugnar la sentencia condenatoria en los cuatro últimos escenarios hipotéticos, los cuales representan un verdadero problema para el ejercicio del derecho en comento, a partir de la consideración de los recursos extraordinarios de casación y de revisión y de la acción de tutela contra providencias judiciales.

\section{Las condiciones normativas para el ejercicio del derecho a impugnar la sentencia condenatoria}

En el contexto de los escenarios hipotéticos comentados, en los cuales existen restricciones al ejercicio del derecho del sindicado a impugnar la sentencia condenatoria, es necesario considerar las condiciones de los medios de impugnación existentes: los recursos extraordinarios de casación -que solo procede en el tercer 
escenario- y de revisión -que procede en todos los escenarios-, y de la acción de tutela contra providencias judiciales.

De entrada, además de la condición excepcional y extraordinaria de las alternativas disponibles, conviene hacer una distinción que puede resultar importante para el análisis ulterior, en torno a la circunstancia prevista en los tratados internacionales examinados, de que la sentencia objeto de la impugnación sea revisada por un tribunal de superior jerarquía. Esta circunstancia puede reconocerse siempre en el trámite del recurso de casación y algunas veces en el trámite del recurso de revisión, cuando el autor de la providencia no es la Corte Suprema de Justicia. El trámite de la acción de tutela también tiene esta dualidad, pues si la tutela se presenta contra una sentencia del tribunal superior de distrito judicial, su conocimiento corresponde a la Sala de Casación Penal de la Corte Suprema de Justicia, que es su superior jerárquico en la jurisdicción ordinaria, pero si se presenta contra esta, su conocimiento le corresponde a la sala de casación civil de la propia Corte, que no es su superior jerárquico.

Esta circunstancia, entre otras, le sirvió durante muchos años a las tres salas de la Corte Suprema de Justicia, en especial a la civil, que la empleó hasta hace muy poco, para sostener que la tutela no puede proceder contra las sentencias de la Corte Suprema de Justicia, pues no existe un superior jerárquico que pueda conocer de ellas, argumento que también puede esgrimirse al momento de considerar la impugnación de las sentencias proferidas por la Sala de Casación Penal de la Corte Suprema de Justicia.

Si la sentencia puede ser revisada por una autoridad que no es, en rigor, un superior jerárquico, como ya ocurre con la acción de tutela contra sentencias judiciales, se abre la posibilidad, que conviene explorar en este documento, de que el derecho a impugnar la sentencia condenatoria no implique de manera necesaria, como parecen indicarlo los tratados internacionales analizados, acudir a un juez o tribunal superior al autor de la sentencia, evento que sería imposible en el caso de que este sea la Sala de Casación Penal de la Corte Suprema de Justicia, a menos que se modificara el ordenamiento jurídico, para crear un órgano judicial superior, lo que implicaría una reforma a la Constitución.

Antes de considerar otros posibles caminos, conviene analizar los ya existentes, como lo hace de manera no unánime la Corte Constitucional en la Sentencia C-792 de 2014, para determinar si ellos son o no adecuados para el ejercicio del derecho del sindicado a impugnar la sentencia condenatoria. La mayoría de la Corte sostiene que no lo son. Este aserto, que es uno de los pilares de su ratio decidendi, puede llevar al riesgo, visible en un salvamento de voto, de asumir una lectura restringida de la expresión impugnar, que es la empleada por la Constitución, para encontrar en ella una sola opción: apelar.

Los caminos existentes en el mejor de los casos -dos recursos extraordinarios y la acción de tutela contra providencias judiciales-, tienen limitaciones en su diseño, procedibilidad y alcance, que hacen de ellos algo diferente a una apelación y 
pueden dificultar la tarea de considerarlos dentro de la expresión impugnar. En el caso de los recursos, el problema material está dado por sus causales, que, además de ser taxativas, demandan una técnica discursiva depurada, y se debe sortear un riguroso proceso de admisión, regido por altos estándares de juicio, pues no es cualquier tipo de irregularidad la que puede dar lugar a su trámite. En el caso de la acción de tutela, la situación no es muy diferente, dado que existe una serie de causales genéricas y específicas de procedibilidad que se debe satisfacer y, aunque se trate de una acción que no requiere de abogado para su ejercicio, no se puede negar que tiene una técnica más depurada que otros tipos de tutela.

En este contexto, la primera alternativa a considerar, que solo es posible en el tercer escenario hipotético planteado, pues se presenta bajo el supuesto de que la condena no haya sido proferida por la Corte Suprema de Justicia ni haya resultado en el trámite del recurso de revisión, es el recurso extraordinario de casación. El antedicho procede contra las sentencias dictadas en segunda instancia, valga decir, por el tribunal superior de distrito judicial, cuando se afecten derechos o garantías fundamentales, siempre y cuando dicha afectación se enmarque en alguna de las siguientes cuatro circunstancias: (i) la falta de aplicación, la aplicación indebida o la interpretación errónea de la norma aplicable, sea esta constitucional o legal; (ii) desconocer el debido proceso o haber afectado de manera sustancial su estructura o la garantía debida a cualquiera de los sujetos procesales; (iii) el manifiesto desconocimiento de las reglas sobre producción y apreciación de la prueba, en la que se funde la sentencia; y (iv) si se trata de controvertir la reparación integral decretada, debe fundarse en las causales y cuantías de la casación civil (art. 181 de la Ley 906 de 2004).

Si bien el propósito del recurso, que es hacer efectivo el derecho material, respetar las garantías de los sujetos procesales, reparar los agravios inferidos y unificar la jurisprudencia (art. 180 de la Ley 906 de 2004), es muy amplio, y su legitimación corresponde a todos los intervinientes que tengan interés (art. 182 de la Ley 906 de 2004), no puede decirse lo mismo de su procedencia, como se acaba de señalar, y de su admisión (art. 184 de la Ley 906 de 2004). Si el fundamento del recurso, que solo es procedente en uno de los cuatro escenarios hipotéticos planteados, no se logra enmarcar de manera precisa en alguna de las causales, es decir en su riguroso estándar, dado por calificaciones explícitas como afectación sustancial o desconocimiento manifiesto e implícitas como la de error manifiesto, sea de hecho o de derecho, o si no se desarrolla de manera satisfactoria para la Corte Suprema de Justicia los cargos de sustentación, o se advierte que no es necesario el fallo para satisfacer alguna de las finalidades del recurso, este no procederá y, por lo tanto, no será admitido.

De tenerse el recurso extraordinario de casación como suficiente para satisfacer el ejercicio del derecho a impugnar la sentencia condenatoria, como sostienen algunas discrepancias a la Sentencia C-792 de 2014, es preciso indicar que, en todo caso, se trataría de una solución muy limitada e insuficiente, en la medida en que apenas responde a un escenario hipotético de entre cuatro posibles y que, además, 
corresponde a una interpretación muy restrictiva de la expresión impugnar, porque si bien los recursos extraordinarios también son medios de impugnación, su alcance, en razón de sus causales, técnica y demás restricciones, es mucho menor que el de los demás medios de impugnación, incluso si se llega a sostener, como no sería imposible de hacer, que en el contexto colombiano el recurso extraordinario de casación puede convertirse en una instancia adicional, la tercera, en el proceso penal.

La segunda alternativa a considerar, que es viable en los escenarios hipotéticos cuarto, séptimo y noveno, es el recurso extraordinario de revisión, denominado por la ley procesal penal: acción de revisión. Si los estándares de las causales de casación se calificaron como rigurosos, los de las causales de revisión son rigurosísimos, pues implican o bien imposibilidades fácticas o jurídicas o evidencia de hechos nuevos que afecten de manera sustancial el juicio o de cambios en la inteligencia de las normas aplicables (art. 192 de la Ley 906 de 2004). La imposibilidad fáctica aparece respecto de la condena de dos o más personas por un delito que no podría haber sido cometido sino por una o por un número menor al de las condenadas. La imposibilidad jurídica es visible cuando el proceso se adelanta pese a la prescripción de la acción penal o a su extinción, o sin que exista querella, en los casos en que es necesaria. La evidencia de hechos nuevos puede ser neutral respecto del proceso mismo o afectar a las partes o al juez. Es neutral cuando aparecen medios de prueba no conocidos en el juicio, de los que resulte la inocencia o inimputabilidad del condenado o sobrevenga una decisión de un tribunal internacional de derechos humanos sobre la falta de investigación seria e imparcial de la vulneración de tales derechos. Es relativa a las partes o al juez, cuando aparece un medio de prueba de que la sentencia fue determinada por un delito del juez o de un tercero, o se fundó en una prueba falsa. El cambio en la comprensión de la norma ocurre cuando la Corte Suprema de Justicia cambia su criterio sobre la responsabilidad o la punibilidad y el mismo es favorable al condenado.

Dadas sus causales que, en rigor, no cuestionan de manera directa la sentencia condenatoria, como lo haría una impugnación, sino más bien escenarios de imposibilidad de la misma, de conductas delictivas o fraudulentas o de cambios favorables en la interpretación de la Corte Suprema de Justicia, por su objeto, el recurso extraordinario de revisión no puede enmarcarse desde el punto de vista material en la expresión 'impugnar', aunque sí pueda considerarse desde la perspectiva formal como un medio de impugnación.

La última alternativa plantea una situación más difícil, pues tiene una amplitud y alcance mayor a la de los dos antedichos recursos extraordinarios y, al mismo tiempo, ofrece una mayor ductilidad en la medida en que sus causales son más amplias. A estas consideraciones debe añadirse que su conocimiento corresponde a un juez diferente al que dictó la condena, aunque no sea de manera necesaria su superior funcional. El problema que plantea la acción de tutela contra providencias judiciales, cuya procedencia es imprescindible para tenerla como alternativa para el ejercicio del derecho del sindicado a impugnar la sentencia condenatoria, 
es el de que esta acción no es un recurso y, por tanto, no puede tenerse como un medio de impugnación.

El que la acción de tutela contra providencias judiciales sea una vía idónea para el ejercicio del control de constitucionalidad sobre la conducta de los jueces, a partir de la revisión de sus actuaciones a la luz de la Constitución y, en especial, de los derechos fundamentales, no se sigue de manera necesaria que pueda tenerse como un recurso más, o mejor, como un último mecanismo, al alcance del sindicado para impugnar la sentencia condenatoria.

Y no puede seguirse así, en primer lugar, porque, como ocurre con los referidos recursos extraordinarios, la acción de tutela puede ser ejercida por otras personas diferentes al sindicado, lo cual da a entender que no se trata de un derecho suyo, sino compartido por varios, como podría decirse del derecho fundamental a una doble instancia. En segundo lugar, aún si se obviara la anterior circunstancia, las causales de procedibilidad de la acción de tutela contra providencias judiciales parecen tener como punto de partida o bien la inexistencia de recursos para impugnar la sentencia o bien el ejercicio de dichos los mismos (requisito de subsidiariedad) y, en cuanto atañe a las causales de procedibilidad específicas, también fijan un estándar más alto que el de un medio de impugnación ordinario, pues los defectos que se predican de la sentencia deben ser también ostensibles o manifiestos y trascendentes, lo cual disminuye significativamente su alcance.

$\mathrm{Al}$ no haber ninguna alternativa que sea adecuada para el ejercicio del derecho del sindicado a impugnar la sentencia condenatoria, como pudo constatarlo la mayoría de la Corte Constitucional en la referida sentencia, y como lo revela este análisis, se está ante una inmensa dificultad: encontrar medios para hacer efectivo el ejercicio del derecho. Tanto la solución de la Corte Constitucional, que en realidad no fue una solución sino una fuente de problemas, como otras posibles soluciones, se considerarán en las dos secciones siguientes.

\section{El ejercicio del derecho a impugnar la sentencia condenatoria}

Es intolerable, en un Estado democrático y social de Derecho, que un derecho o garantía fundamental, sobre cuya existencia no hay duda ni controversia, no pueda ejercerse por la carencia de medios idóneos en el ordenamiento jurídico. Y es aún más insoportable que esta situación se prolongue, al parecer de manera indefinida, en el tiempo.

El discurso de la Corte Constitucional, que es prolijo en el reconocimiento del derecho del sindicado a impugnar la sentencia condenatoria, al que distingue del derecho a la doble instancia, se encauza en un camino que conduce, con alta probabilidad, a dos sin salidas: una imputable a la propia Corte, que de manera injustificada cercena el derecho al ocuparse de su ejercicio, y, otra, imputable a la omisión de otras autoridades del Estado, en especial al Congreso y a la judicatura. 
Para comprender lo dicho sobre las sin salidas del camino, es menester recorrerlo e indicar cuáles son los puntos de ruptura, como se hace enseguida. El recorrido parte de dos bases ciertas y evidentes: (i) el derecho fundamental del sindicado a impugnar la sentencia condenatoria y su correlativo derecho humano en la CADH y en el PIDCP, son diferentes al derecho a la doble instancia; y (ii) los medios existentes en el actual diseño del ordenamiento jurídico colombiano: los recursos extraordinarios de casación y de revisión y la acción de tutela contra providencias judiciales, no son adecuados ni suficientes para ejercer dicho derecho fundamental, por sus estándares. En efecto, como lo destaca la Corte, el ejercicio del derecho requiere de (i) un examen amplio de los elementos normativos, fácticos y probatorios; (ii) el análisis sobre la controversia base y solo en segundo lugar sobre el fallo judicial; y (iii) la revisión de la decisión judicial debe ser abierta y no limitada por un conjunto de causales.

El camino prosigue por considerar que, de la falta de idoneidad y suficiencia de los medios existentes, se sigue que no hay ningún medio adecuado para ejercer el derecho fundamental del sindicado a impugnar la sentencia condenatoria y, por esta vía, se afirma que las normas pertinentes de la Ley 906 de 2004 incurren en una omisión normativa. La omisión no se califica, aunque podría tenerse de manera plausible como relativa, dado que su contenido 'positivo' a la postre se declara exequible. Ante la existencia de la omisión, la Corte Constitucional toma tres decisiones relevantes para este análisis: declara la inconstitucionalidad de las normas demandadas en cuanto "omiten la posibilidad de impugnar todas las sentencias condenatorias" y, en consecuencia, exhorta al Congreso para que, en el término de un año, regule el ejercicio del derecho fundamental $y$, en caso de que este deber no se cumpla en el término fijado, dispone que "se entenderá que procede la impugnación de los fallos anteriores ante el superior jerárquico o funcional de quién impuso la condena".

La declaración de inexequibilidad de las normas demandadas, en cuanto a lo que omiten, si bien parece algo heterodoxa frente al reconocimiento del hecho de la omisión legislativa relativa, no genera reparos de fondo porque es otra forma de decir lo mismo e, incluso, puede dar a entender con mayor claridad que incumplir un deber constitucional, en este caso en la configuración legal del régimen del proceso penal, es contrario a la Constitución. Lo que sí genera problemas y merece ser sometido a la crítica es lo relativo a las consecuencias que se siguen de esta declaración y a las implicaciones que podrían derivarse de ellas.

La parte menos sólida de la construcción argumental y, además, la que genera más problemas prácticos, es la atinente a la condición estructural de la omisión legislativa. En efecto, la sentencia señala que prever un recurso judicial que permita ejercer el derecho del sindicado a impugnar la sentencia condenatoria "constituye un elemento estructural del proceso, $y$, por tanto, se proyecta en toda la normativa procesal penal, y además, implica el rediseño de una amplia gama de instituciones". La condición de estructural de la omisión es la que impide a la Corte Constitucional proferir una sentencia aditiva y conduce a la que ha probado ser una 
salida poco afortunada en la historia reciente: una exhortación condicionada al Congreso de la República.

El estudio de los escenarios hipotéticos y su complejidad, parece confirmar la afirmación de que la omisión tiene carácter estructural y, por tanto, el corolario de que para subsanarla se requiere un profundo rediseño del régimen jurídico procesal penal, que el juez constitucional no puede hacer en una sentencia. No obstante, en razón de la historia reciente, pues el legislador todavía no se toma en serio ni sus deberes constitucionales (en este caso el de dictar normas para hacer posible el ejercicio de un derecho fundamental y humano), ni asume con prontitud sus responsabilidades (atender en tiempo la exhortación), no era descabellado asumir la posible situación de que se cumpliera el término fijado y no se hubiere hecho el susodicho rediseño, alternativa para la cual la sentencia tiene una pobrísima e incompleta respuesta, como es la de decir que en caso de que el legislador incumpla su deber, "se entenderá que procede a impugnación de los referidos fallos ante el superior jerárquico o funcional de quien impuso la condena".

Existe en realidad un contrasentido en asumir, por una parte, que la omisión tiene un carácter estructural y disponer, por otra, que puede subsanarse con un mero mandato en el sentido de que se entenderá que procede la impugnación. Esto, además de no ser coherente con el propio dicho, resulta en la práctica inviable, como lo demuestra la experiencia de la Corte Suprema de Justicia, que se niega a admitir cualquier tipo de impugnación mientras no se reforme la ley e, incluso, la Constitución, pues, de manera comprensible, ningún juez ordinario, en especial un juez penal, está dispuesto a tomar para sí o dejar para otro una competencia no prevista en la ley.

El diferimiento de los efectos de la sentencia, que es un elemento necesario para que se pueda cumplir con la exhortación en el plazo fijado, genera un importante problema para el ejercicio del derecho fundamental en el tiempo. Y es que este ejercicio, en rigor, no solo es posible a partir de la fecha del diferimiento, ni siquiera de la fecha de la sentencia, sino que, al estar el derecho fundamental del sindicado a impugnar la sentencia condenatoria previsto en el texto de la Constitución, su ejercicio debe ser posible al menos a partir de la vigencia de la misma, para no hablar de lo que sería si se extiende en el tiempo la proyección a la vigencia de la CADH o del PIDCP, que es anterior a la de la Constitución.

La declaración de inconstitucionalidad con efectos diferidos, que se tiene como necesaria para la exhortación al Congreso de la República, que sería, a su vez, necesaria para subsanar la omisión de carácter estructural, tiene un alto costo en materia de derechos fundamentales, que hace necesario su análisis y crítica. El efecto diferido impide, al menos prima facie, a las personas condenadas antes de que se cumpla el plazo de un año fijado por la sentencia, ejercer el derecho a fundamental a impugnar la sentencia condenatoria, pese al claro mandato constitucional al respecto y, además, pone a estas personas en una situación de clara diferencia de trato respecto de aquellas cuya condena sobrevenga después el plazo, a quienes sí se les 
permite ejercer el derecho, dando lugar a una discriminación injustificada, pues su único fundamento es el que la Corte Constitucional acaba de advertir la existencia de un derecho, que antes no había notado. A esto debe agregarse lo incomprensible que resulta la limitación del ejercicio del derecho a partir del principio de favorabilidad.

Podría sonar maximalista y hasta peligroso, pero es lo que corresponde, sostener que todos los sindicados que hayan sido condenados, al menos después de la vigencia de la Constitución Política, si no tuvieron la oportunidad de impugnar la sentencia condenatoria, conforme a los escenarios hipotéticos planteados, deben tenerla a partir del plazo fijado por la Corte Constitucional. Esto puede poner en entredicho muchas condenas proferidas por la Corte Suprema de Justicia, de las cuales sería muy difícil afirmar que están en firme, si se acepta que existe un recurso por ejercer, pero ese es el precio de tomarse en serio la Constitución y, en especial, los derechos fundamentales.

Con la modulación de la sentencia, esta posibilidad se cercena (acaso en razón de la seguridad jurídica) y, lo que es más grave, se mutila el ejercicio de un derecho fundamental que solo sería posible a partir del reconocimiento hecho por el juez constitucional, en los términos de su sentencia diferida. Así suene muy fuerte decirlo, la Corte Constitucional acertó al declarar la inconstitucionalidad de las normas en cuanto omiten, pero no lo hizo al hacer esta declaración con efectos diferidos, para cercenar de manera que parece definitiva el ejercicio de un derecho fundamental de muchos sindicados condenados, aunque en esta materia todavía podría haber algo más que decir en otros escenarios o foros, en especial por tribunales internacionales. Si un condicionamiento era necesario, ha debido ser el de declarar la inconstitucionalidad con efectos retroactivos y, por esta vía, conformar la unidad normativa con las expresiones semejantes contenidas en normas anteriores a la Ley 906 de 2004, para permitir que, al menos a partir de la vigencia de la Constitución de 1991, el derecho fundamental del sindicado a impugnar la sentencia condenatoria pudiera ser ejercido.

La pretendida necesidad del condicionamiento, puede y debe cuestionarse a partir de sus propios referentes. Si bien parece plausible asumir que se está ante una omisión de carácter estructural, también debe tenerse en cuenta que se trata del ejercicio de un derecho fundamental que, en los tratados internacionales, es considerado como una garantía mínima. Además, aún en el caso de que se considere necesaria la exhortación, no se ve por qué la ley no podría regular el ejercicio del derecho para personas condenadas antes de que se hubiere proferido la sentencia o de que se cumpliese el término del diferimiento, para brindarles, así sea tarde, la posibilidad de ejercer un derecho fundamental y humano. Lo que en realidad no se entiende en esto es que lo sacrificado, en aras de la seguridad o de la estabilidad del sistema jurídico, sea -justo es decirlo- el ejercicio de un derecho fundamental y no la cosa juzgada aparente, a la cual hicieron tránsito un buen número de decisiones sin que se hubiera respetado dicho derecho; sin embargo, la decisión de la Corte Constitucional parece inclinarse por la segunda alternativa. 
La conclusión a la que llega la sentencia, cuando prevé el eventual incumplimiento del Congreso de la República de su deber, así como su indiferencia ante la gravedad de esta circunstancia, merecen también un análisis y una crítica especiales. El que el Congreso de la República incumpla su deber, más allá de ser una circunstancia constatable en el contexto del control de constitucionalidad y de la historia, debe ser el fundamento para desarrollar una verdadera teoría de la responsabilidad tanto de la institución como de sus miembros. A los evidentes daños patrimoniales que de esta omisión se siguen para los sindicados, algunos de los cuales podrían haber llegado a estar privados de manera injusta de su libertad, y de sus familias, que podría encausarse en la responsabilidad del Estado por el hecho del legislador y completarse por medio de la acción de repetición, contra quienes, pese a ser exhortados a cumplir con su deber, no lo hicieron y todavía no lo hacen, debe agregarse el eventual compromiso de su responsabilidad disciplinaria e incluso de naturaleza penal. No sobraría que la Corte Constitucional advirtiese estas circunstancias evidentes -aunque al parecer desapercibidas- al Congreso de la República cuando se empeñe en exhortarlo a cumplir con su misión.

En eventos como este, así se trate de una sentencia de control abstracto de constitucionalidad, al haber deberes por cumplir con posterioridad a su comunicación y notificación, valdría la pena explorar la figura del trámite de cumplimiento, para que sea la propia Corte la que, en un trámite posterior a la sentencia, tome las medidas que sean necesarias para hacer un seguimiento a sus decisiones y para verificar su cumplimiento oportuno. Esta posibilidad, que admite fórmulas intermedias, como las de dejar la tarea de verificar el cumplimiento de la sentencia en órganos que tienen esta competencia constitucional, como es el caso de la Procuraduría General de la Nación (art. 277.1 CP), cobra mayor importancia cuando se trata de una sentencia que declara la inconstitucionalidad de una omisión legislativa, pues, en tal caso, para que la vulneración a la Carta cese, no basta con la declaración del tribunal constitucional, sino que se requiere de la acción del Congreso de la República.

Si se decide, como en efecto se hace, permitir la impugnación si se dan unas condiciones, que se dieron en este caso, la Corte Constitucional no puede limitarse a decir que entenderá que esta procede, pues, por esta vía, no subsana la omisión estructural, sino que genera al menos dos notables problemas nuevos: el de saber las condiciones de la procedencia de la impugnación (plazos, juez competente, alcance y sentido) y el de lograr que dicha impugnación sea, en efecto, tramitada por la jurisdicción. Si se va a entender que la impugnación procede, la Corte Constitucional debería tomarse el trabajo, así parezca una usurpación de la competencia del ente al cual exhorta, de fijar al menos unas condiciones mínimas de procedencia, relacionadas con la oportunidad, la legitimidad, el alcance y el efecto de la impugnación, y unas condiciones mínimas de trámite, que podrían ser las previstas para un recurso ordinario conocido. $Y$, además, debe señalar una vía para lograr que dicha impugnación sea tramitada por la jurisdicción, que bien puede ser una acción de tutela para lograr el cumplimiento de la Constitución y de la sentencia de constitucionalidad, o un incidente o solicitud de cumplimiento de 
la sentencia. Lo que no puede hacer, como lo hizo, es decir que entenderá que el derecho se puede ejercer y nada más, pues de esta manera ni la Constitución ni su sentencia se cumplen, por muchos motivos que se pueden aducir, algunos de ellos razonables y, lo que es mucho más grave, se deja trunco y frustrado el ejercicio de un derecho fundamental y humano.

Estas omisiones de la Corte Constitucional, acaso comprensibles en su ejercicio de moderación y de autocontención, además de dar al traste con el ejercicio del derecho fundamental en comento, revelan una inteligencia limitada de su alcance. En efecto, la comprensión que se hace del derecho fundamental, con tantas acotaciones temporales para su ejercicio, no parece ser conforme al principio pro persona. Tampoco parece adecuada a este principio la interpretación, acaso inspirada en el texto de los tratados internacionales sobre derechos humanos, de considerar que el derecho a impugnar la sentencia condenatoria deba ejercerse ante el superior jerárquico o funcional de quien impuso la condena. Esta consideración, si bien precisa el derecho reconocido en el art. 29 de la Constitución, que no dice nada respecto del juez ante el cual debe tramitarse la impugnación, en el sentido de que el funcionario que conoce de la impugnación debe ser diferente al juez que profirió la sentencia (lo que descalifica el recurso extraordinario de revisión cuando su objeto son las decisiones de la Corte Suprema de Justicia), lo acota de tal manera que exige un superior jerárquico, lo cual le brinda a la Corte Suprema de Justicia la oportunidad de afirmar que ella no tiene dicho superior, por lo cual el ejercicio del derecho no es posible.

Una interpretación sistemática de la Constitución y de los tratados internacionales sobre derechos humanos (CADH y PIDCP), orientada por el principio pro personae, debe precisar el alcance del derecho, pero sin incorporar restricciones injustificadas a su ejercicio. En el contexto de ambos tratados, acaso parezca plausible hablar de superior jerárquico o funcional, porque lo ordinario es que la primera sentencia condenatoria sea proferida por un juez inferior. Sin embargo, la configuración legal del proceso penal en la República de Colombia, como se advirtió al plantear los escenarios hipotéticos, permite que la sentencia condenatoria sea proferida por primera vez por el tribunal de cierre de la jurisdicción ordinaria: la Corte Suprema de Justicia.

Como ya se indicó atrás, en el ordenamiento jurídico colombiano es posible hablar de impugnaciones que, si bien son conocidas por jueces o tribunales diferentes de aquel que dictó la sentencia, no son en rigor sus superiores jerárquicos o funcionales. Tal es el caso de las otras Salas de la Corte Suprema de Justicia, en el proceso de tutela, tanto para su conocimiento en primera instancia como para su impugnación.

En vista de la anterior circunstancia, una interpretación pro personae, fiel al propósito de garantizar el ejercicio del derecho antes que al de asumir con paciencia las disfuncionalidades el ordenamiento jurídico, así fuese de manera provisional, mientras el legislador diseña un régimen integral, y a pesar de la crítica que puede 
hacerse, con razón, a partir del principio de especialidad, habría podido emplear la experiencia del proceso de tutela y señalar que la impugnación de las sentencias condenatorias proferidas por la Sala Penal de la Corte Suprema de Justicia, debía ser tramitada ante la Sala Civil de la misma, o incluso, si se quiere dejar incólume el principio de especialidad, señalar que la impugnación debería ser conocida por la propia Sala de Casación Penal de la Corte Suprema de Justicia integrada por magistrados o, de no haberlos, por conjueces, que no hubieren participado en la sala que profirió la sentencia. De esta manera, se respetaría la precisión de que la impugnación la debe conocer un juez distinto al que profirió la sentencia, pero no se sacrificaría el ejercicio del derecho, en los múltiples escenarios hipotéticos en los cuales ésta correspondió a la autoría de la Sala de Casación Penal de la Corte Suprema de Justicia.

\section{Conclusiones}

Al no haber diseñado un mecanismo legal idóneo para el ejercicio del derecho a impugnar la sentencia condenatoria, el Congreso de la República incurre, como lo señala la Sentencia C-792 de 2014, en una omisión legislativa.

Esta omisión compromete la responsabilidad del Estado en el plano interno: al impedir el ejercicio de un derecho fundamental (art. 29 CP) y en el plano internacional: al no respetarse un derecho humano (art. 1.1 CADH y 2.1 PIDCP) y no haberse adoptado las medidas necesarias para hacerlos efectivos (art. 2 CADH y 2.2 PIDCP).

Si bien la Corte declaró inexequible la ley procesal penal en cuanto a lo que omite, esta declaración no ha debido hacerse con efecto diferido sino con efecto retroactivo, conforme a la preexistencia del derecho en la Constitución y en los tratados internacionales sobre derechos humanos respecto de la Sentencia C-792 de 2014 y en atención a los principios de igualdad de trato y de favorabilidad.

El derecho fundamental del sindicado a impugnar la sentencia condenatoria, debe interpretarse conforme a los tratados internacionales sobre derechos humanos ratificados por la República de Colombia (art. 93 inc. 2 CP); esto implica dilucidar el texto que reconoce el derecho constitucional conforme a los instrumentos que reconocen los derechos humanos correlativos y, además, conforme a las reglas hermenéuticas previstas en dichos tratados, en especial al principio pro persona. Al interpretar el derecho fundamental del sindicado a impugnar la sentencia condenatoria en los anteriores términos, se tiene que no es viable introducir restricciones temporales a su ejercicio (como se hace con el condicionamiento diferido), ni asumir de manera necesaria que la impugnación deba ser conocida por un juez superior jerárquico o funcional del juez que profiere la condena, aunque sí por un juez diferente de este. 


\section{Referencias}

Arango, M. (2004). El bloque de constitucionalidad en la jurisprudencia de la Corte Constitucional colombiana. Precedente- Anuario Jurídico, (s.n.),79-102.

Caballero, J. L. (2011). La cláusula de interpretación conforme y el principio pro persona (Artículo 1 y segundo párrafo, de la Constitución). En M. Carbonell y P. Salazar (coords.), La reforma constitucional de derechos humanos: un nuevo paradigma Cuestiones constitucionales (pp. 103-133). México: UNAM.

Cajas, M. (2015). La historia de la Corte Suprema de Justicia de Colombia, 1886-1991, 2 t. Bogotá-Cali: Universidad de los Andes y Universidad ICESI.

Cifuentes, E. (2000). Informe sobre la jurisdicción constitucional en Colombia. Ius et Praxis, 6(2), 63-81.

Constitución Política (1991). Congreso de la República de Colombia. Colombia.

Ferrer, E. (2011). Interpretación conforme y control difuso de convencionalidad. El nuevo paradigma para el juez mexicano. Estudios Constitucionales, 9(2), 531-622.

Fonseca, M. (1992). Las fuentes formales del derecho colombiano a partir de la Nueva Constitución. Revista de Derecho, Universidad del Norte, (1), 32-45.

Gómez, L. (2001). El control constitucional en Colombia. Evolución histórica, Bucaramanga: UNAB.

Henderson, H. (2004). Los tratados internacionales de derechos humanos en el orden interno: la importancia del principio pro homine. Revista IIDH, (39), 71-99.

Hinestrosa, F. (2000). De los principios generales del Derecho a los principios generales del contrato. Revista de Derecho Privado, (5), 12-22.

Ley 153 de 1887. Por la cual se adiciona y reforma los códigos nacionales, la Ley 61 de 1886 y la Ley 57 de 1887. Congreso de la República de Colombia, agosto de 1987.

Ley 600 de 2000. Por la cual se expide el Código de Procedimiento Penal. Diario Oficial No. 44.097. Congreso de la República de Colombia, julio de 2000.

Ley 906 de 2004. Por la cual se expide el Código de Procedimiento Penal. Diario Oficial No. 45.658. Congreso de la República de Colombia, septiembre de 2004.

López, D. (2006). El papel de los jueces y la jurisprudencia en la Constitución de 1886: apuntes históricos sobre la Corte de Casación de la Regeneración. En R. Sanín y C. Bernal, Justicia Constitucional: el rol de la Corte Constitucional en el estado contemporáneo (pp. 25-46). Bogotá: Legis y Pontificia Universidad Javeriana.

Mendieta, D. (2010). La acción pública de inconstitucionalidad: a propósito de los 100 años de su vigencia en Colombia. Universitas (120), 61-84. 
Moreno, L. J. (2010). El sistema de control constitucional en Colombia. Civilizar 10(19), 75-92.

Moreno, L. J. \& Lozano, C. E. (2011). Fuero y desafueros. Bogotá: Universidad Sergio Arboleda.

Olano, H. A. (2005). El bloque de constitucionalidad en Colombia. Estudios Constitucionales, 3(1), 231-242.

Organización de los Estados Americanos [OEA]. (22 de Noviembre de 1969). Convención Americana sobre Derechos Humanos. Pacto de San José de Costa Rica. Costa Rica.

Organización de las Naciones Unidas [ONU]. (1976). Pacto Internacional de Derechos Civiles y Políticos. Nueva York.

Sagüés, N. (2010). Obligaciones internacionales y control de convencionalidad. Estudios constitucionales, 8(1), 117-136.

Santolaya, P. (2013). La apertura de las constituciones a su interpretación conforme a los tratados internacionales. En E. Ferrer \& A. Herrera (Coords.), Diálogo jurisprudencial en derechos humanos. Entre tribunales constitucionales y cortes internacionales (pp. 447-456). Madrid: Tirant lo Blanch.

Sentencia C-792 (2014, octubre 29). Demanda de Inconstitucionalidad. M.P. Luis Guillermo Guerrero Pérez. Corte Constitucional.

Tamayo, J. \& Jaramillo, C. I. (2012). El precedente judicial en Colombia. Papel y valor asignados a la jurisprudencia. Bogotá: Ibáñez.

Yepes, H. (2012). Prólogo. En J. Tamayo \& C. I. Jaramillo, El precedente judicial en Colombia. Papel y valor asignados a la jurisprudencia. Bogotá: Ibáñez. 